\title{
Non-destructive methods as a tool in the assessment of monumental buildings condition
}

\author{
G. Concu \& B. De Nicolo \\ Department of Structural Engineering, Cagliari University, Italy
}

\begin{abstract}
Results of a diagnostic campaign carried out on ancient Santa Maria Church in Oristano (Italy), with the purpose of evaluating the structural condition before starting a restoration program, are reported. The beautiful building showed signs of damage such as cracks, gathered especially on the façade's masonry and on the accessing arches of the lateral chapels contiguous to the façade. With the aim at non-invasively getting the higher number of reliable data about the real static condition of the church's façade and its out-buildings, several non-destructive investigations have been carried out. As a first step a global visual inspection has been run. Then, sonic tests, endoscopy and flat jacks have been carried out on the façade's masonry, and a dynamic test has been run on the tie rods that link the façade to the lateral chapel's masonries. Finally, the development of the cracks in the arches has been monitored for a period of fourteen months.

Keywords: stone masonry, non-destructive testing, sonic test, flat jacks, rod ties tension, crack pattern.
\end{abstract}

\section{Introduction}

Buildings preservation and restoration is a complex problem to deal with, especially when concerning buildings of historical relevance: the evaluation of the real state of the structure should not interfere with the condition and the functionality of the building and possibly with limited costs. A costs to benefits analysis should be run, taking into account the economic-social-cultural importance of the building and principally the damage caused to things and people by possible failure and collapse of the structure. In this context, the inspection and monitoring of structural condition have become essential parts of the life-cycle management of monumental buildings. In fact, outputs from 
inspections and assessments of a structure become inputs into maintenance, rehabilitation and replacement strategies, with the objective to ensure public safety, to monitor the structural performance, to identify deficiencies and thus to facilitate immediate intervention. In this light, it is essential to understand the mechanism of structures deterioration, since its accurate modelling is the most critical component in maintenance management of buildings heritage. Under this situation, developments in non-destructive techniques (NDTs) as methodologies for monumental building assessment have grown significantly in recent years [1-4], because the use of these inspection techniques allows one to acquire several relevant data not interfering with the state of the asset, thus permitting to properly plan the intervention of rehabilitation and to prepare and manage maintenance budgets. Since the diagnosis of the degrade level depends on the damage indicators (cracks diffusion, sound velocity, etc.) measured during the inspection and associated to the chosen inspection method, the choice of the diagnostic system more suitable to the actual analysis, as well as the correct interpretation of the survey results, become crucial. In the present paper a case study regarding the use of several NDTs as a tool in the assessment of monumental buildings condition is reported. The building is ancient Santa Maria Church in Oristano (Italy).

\section{The Church}

Santa Maria Church (1130) was rebuilt during the reign of Mariano II after being destroyed in a siege. Of the original structure of Mariano only parts of the apse and base of the bell tower are left, as well as the Gothic Chapel of the Rimedio, which houses some medieval sculptures. Parts of a more ancient Byzantine edifice can be seen in the court. The church was restored in the $17^{\text {th }}$ century, but 3 chapels were left in the ancient Romanesque style. The current Baroque style comes from a $19^{\text {th }}$ century restoration. The northern side of the building is joined by the beautiful medieval bell tower, having octagonal cross-section and finished in the $17^{\text {th }}$ century with a dome majolica-covered. The façade is made of regular trachite blocks. The interior has a Latin cross plant, and is made by a single wide nave with three chapels on each side, a square apse and a quadrangular transept. The intersection between the nave and the transept is covered by the octagonal dome (fig. 1).

\section{Visual inspection and surveys planning}

Visual inspection showed that several interventions had been carried out on the façade over the centuries. They were given evidence by building materials of different size and lithologic type, and by different building techniques. The presence of three anchors, two of which belonging to the rod ties of the lateral chapels contiguous to the façade, might signify that some intervention aimed at eliminating pushes on the façade was carried out in the past. 

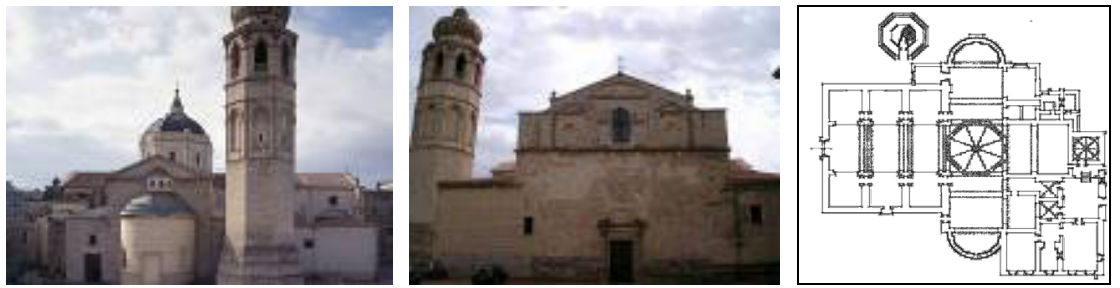

Figure 1: $\quad$ From left to right: northern view, façade, cross section.
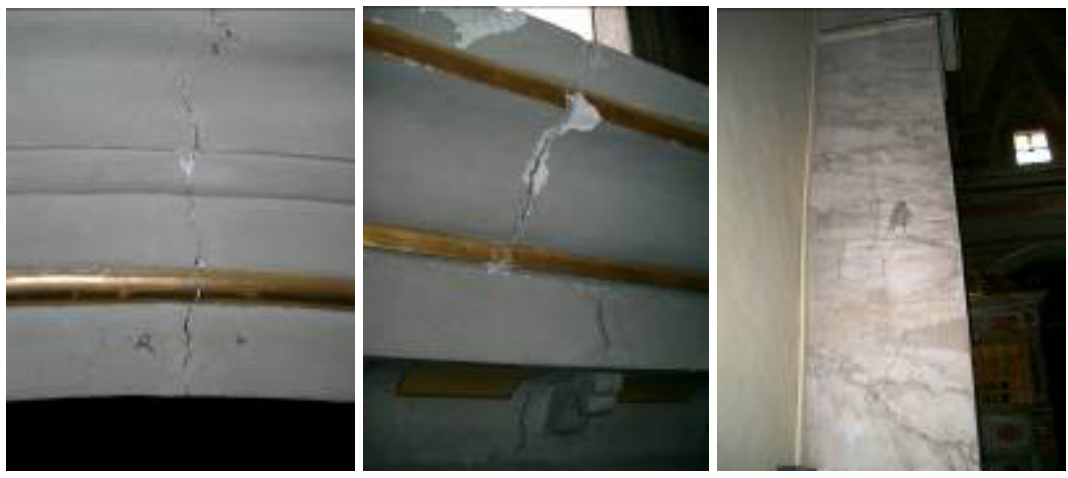

Figure 2: Crack patterns. From left to right: middle of arches, above arches, along the joint façade-walls.

The accessing arches of the lateral chapels contiguous to the façade showed visible crack patterns (fig. 2):

- $\quad$ in the middle of the arches

- $\quad$ on the masonry above the arches, at an angle of about $45^{\circ}$ towards the façade and developing towards the ledge

- $\quad$ along the vertical joints between the façade and the chapels lateral walls.

Some of the cracks seemed to have been compensated in the past.

On the basis of visual inspection's outcomes, it has been chosen to carry the NDTs on masonries of the façade and of the accessing arches of the lateral chapels contiguous to the façade, with the purpose of evaluating their actual static condition. Thus, the following diagnostic surveys have been planned:

- cracks monitoring, in order to understand the on-time mechanical behaviour of arches and façade

- $\quad$ sonic tests, endoscopy and flat jacks on the façade's masonry, with the aim of assessing structural typology, materials health and stress level

- dynamic test on the tie rods linking the lateral chapels vault to the façade.

\section{Cracks monitoring}

Cracks occur in most buildings and civil engineering structures. Monitoring the changes in crack width is an important diagnostic technique for determining the 
cause and specifying the remedial work. Crack monitors are used to determine the extent of structural problems. The crack gauges monitor the movements across a crack over a period of time to determine what structural problems exist. A crack monitor can be used to determine whether existing cracks in the historic building are stable or still experiencing movement.

Monitoring of cracks has been set up in order to assess possible risks and to understand the mechanical behaviour of the structures before planning any kind of intervention. Aiming at evaluating the differential movement of the arches and the façade, the most serious cracks have been monitored for 14 months. The displacements have been measured by a digital extensometer having \pm 1 micron accuracy. In the detail, the monitoring interested 8 cracks, located on the middle of the two arches and on the above masonry (fig. 3). The trend of cracks displacements is reported in fig. 4. Right and left positions are referred to an observer with backs to the apse.

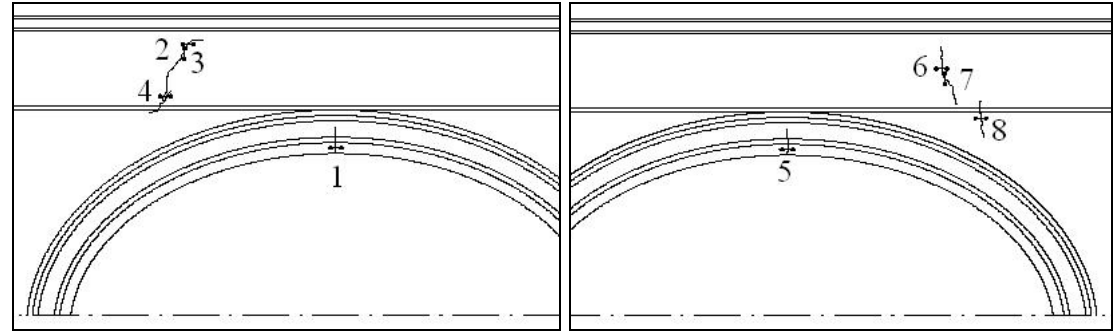

Figure 3: Monitored cracks. Left: right arch, points 1-4. Right: left arch, points 5-8.

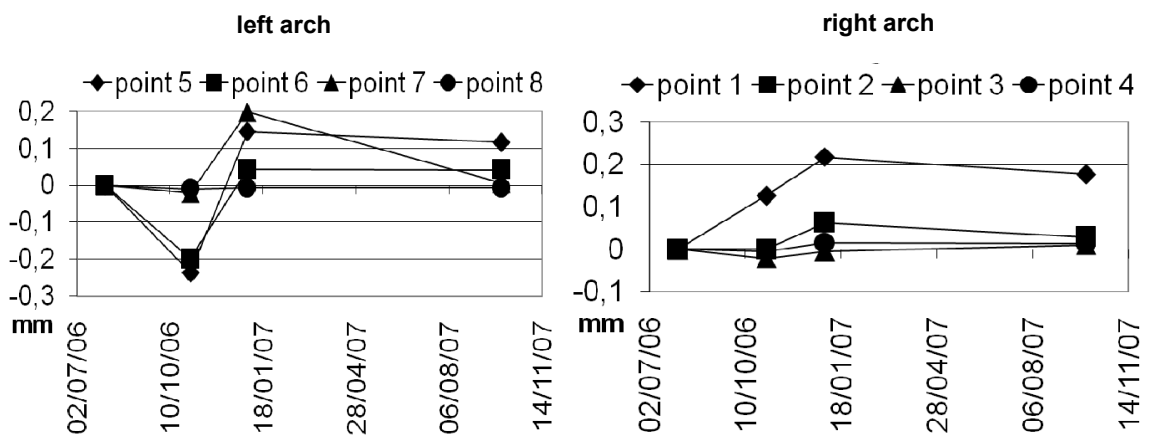

Figure 4: $\quad$ Trend of cracks displacements.

Collected data pointed out the following results:

- the two arches showed quite similar behaviour, with a maximum displacement of about $10,21 \mathrm{~mm}$

- displacements trend seemed to depend on temperature's changes: cracks experienced the top closing at the end of the summer, when materials reach their maximum dilatation, and the top opening during the winter 
- displacements trend was quite sinusoidal, with very low time-increasing amplitude for points 1 and 5 .

\section{NDTs for masonry qualification}

Sonic tests, endoscopy and single flat jacks have been carried out on the façade's masonry, at different levels. Sonic tests provide a preliminary detection of masonry characteristics and can suggest the choice of the area for flat jack tests, whilst endoscopy allows the inspector to check masonry characteristics in single points by direct vision. For these reasons the masonry qualification has been obtained by the complementary use of the above mentioned NDTs. Tested areas are shown in fig. 5 .

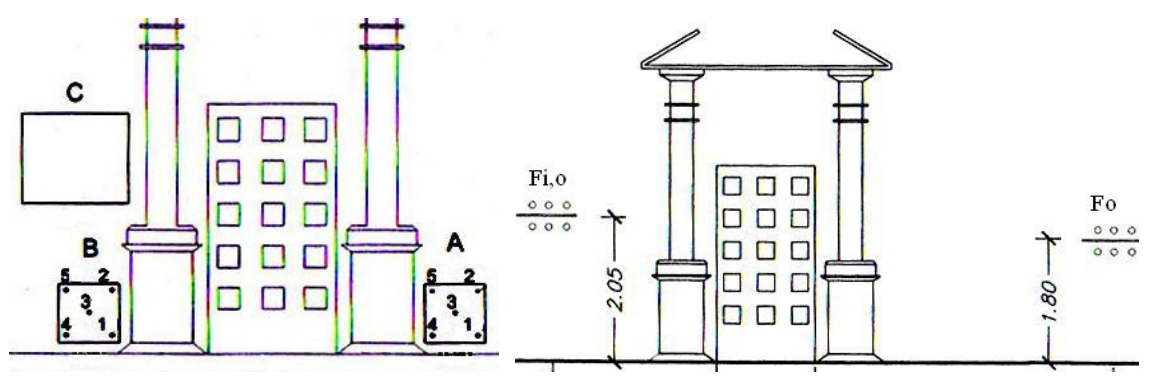

Figure 5: Left: areas A, B, C tested by sonic technique; points $1 \mathrm{~A}-5 \mathrm{~A}$ and 1B-5B tested by endoscopy. Right: areas $\mathrm{F}_{\mathrm{i}, \mathrm{o}}$ and $\mathrm{F}_{\mathrm{o}}$ tested by flat jacks.

\subsection{Sonic tests}

Sonic materials analysis is based on a simple principle of physics: the propagation of any wave will be affected by the medium through which it travels. Thus, changes in measurable parameters associated with the passage of a wave through a material can be correlated with changes in physical properties of the material. Traditional application of the sonic technique is based on measurements of the velocity $v$ of transient stress waves propagating through the material along selected paths. The velocity is obtained from the ratio $l / t$, where $t$ is the time wave needs to travel along the path of length $l$. The velocity is affected by inner geometry and material physic-mechanic characteristics (dynamic elastic modulus, Poisson's number and density) and serves to evaluate homogeneity of the masonry and presence of possible discontinuities $[5,6]$.

Sonic tests have been carried out applying the Direct Technique, in which the sonic wave is transmitted by a transducer through the tested structure and received by a second transducer on the opposite side. The propagation time $t$ has been measured along paths crossing the thickness of the walls and located at a mutual distance of $0,20 \mathrm{~m}$. After extracting the velocity $v$, its values have been interpolated for elaborating a velocity map. The testing equipment included: 

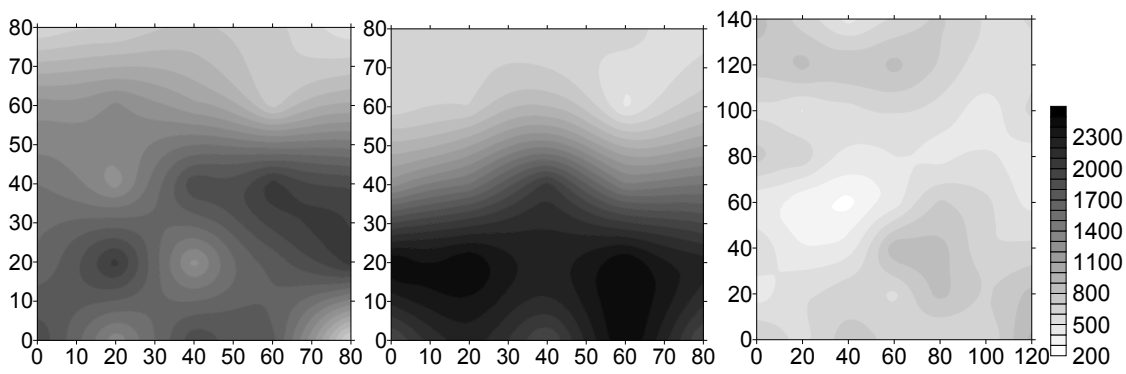

Figure 6: Distribution of sonic velocity $(\mathrm{m} / \mathrm{s})$. From left to right: area A, area $\mathrm{B}$, area $\mathrm{C}$ (length is in $\mathrm{cm}$ ).

- $\quad$ an impact hammer with piezoceramic sensor for emitting signals

- $\quad$ a $55 \mathrm{kHz}$ piezoelectric transducer for receiving signals

- a digital oscilloscope for signal visualisation and preliminary analysis

- a PC for data storage and signal processing.

Transparent Vaseline was used to couple the receiving transducer to the masonry, in order to reduce energy dissipation due to the different acoustic impedance between materials in contact.

The velocity maps of tested areas are shown in fig. 6 .

The analysis of sonic velocity distributions pointed out the following results:

- $\quad$ areas $\mathrm{A}$ and $\mathrm{B}$ showed $v$ values within the range $500-2500 \mathrm{~m} / \mathrm{s}$, with mean value of about $1400 \mathrm{~m} / \mathrm{s}$ and standard deviation of about $600 \mathrm{~m} / \mathrm{s}$

- $\quad$ area $\mathrm{C}$ showed $v$ values within the range $300-900 \mathrm{~m} / \mathrm{s}$, with mean value of about $600 \mathrm{~m} / \mathrm{s}$ and standard deviation of about $150 \mathrm{~m} / \mathrm{s}$

- $\quad$ sonic velocity of areas A and B decreased from bottom to top, while in area $\mathrm{C}$ the distribution is quite uniform.

\subsection{Endoscopy}

Endoscopy is a very practical technique in structural diagnostics as it offers the chance to see directly shape and appearance of elements otherwise inaccessible to direct observation, making it possible to carry out useful evaluations. The endoscopes can therefore be used in the on-site examination of both natural and artificial cavities, in order to directly observe morphology, type and state of conservation of materials and structures or structural elements that can be conveniently surveyed through small-diameter holes [7, 8].

Ten endoscopic surveys have been carried out on previously sonic-tested areas $\mathrm{A}$ and $\mathrm{B}$, using a modular rigid endoscope. Inspections have been run through holes drilled in points located at the edges and in the centre of the areas, as shown in fig. 5-left, aiming at correlating discontinuities in the $v$ maps and masonry inner characteristics. During the test 181 pictures have been acquired by a camera connected to the endoscope. These pictures showed a quite regular masonry and highlighted that the non-homogeneity level increases towards the masonry core. Some pictures acquired during the surveys are shown in fig. 7. 

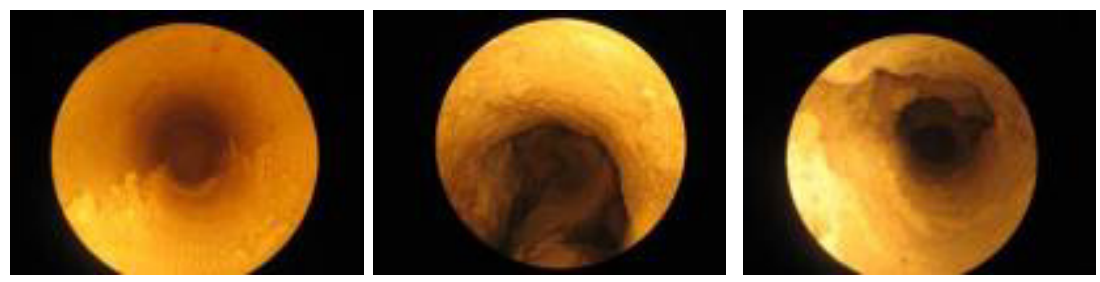

Figure 7: Endoscopic pictures. Left: survey 4B, high regularity. Centre: survey $1 \mathrm{~A}$, high non-homogeneity. Right: survey $1 \mathrm{~B}$, high nonhomogeneity.

\subsection{Flat jacks}

The single flat jack test provides the values of the vertical compressive stress in masonry walls under loads. The test is only slightly destructive and it is carried out by introducing a thin flat-jack in place of a mortar layer which has been cut. After the test is completed, the flat-jack can easily be removed and the mortar joint restored to its original condition. The determination of the state of stress is based on the stress relaxation caused by a cut perpendicular to the wall surface; the stress release is determined by a partial closing of the cutting, i.e. the distance between the edges of the slot after the cutting space is lower than before. A thin flat-jack is placed inside the slot and the pressure is gradually increased to restore the distance measured before the cut. The displacements caused by the cut and those subsequently induced by the flat-jack are measured by a removable extensometer before, after cutting the slot and during the tests. Even if this test was firstly set up for brick-masonries, it has now been developed also for stonemasonries made with irregular stones. The experience coming from several cases of application has permitted to generally define the level of reliability, the advantages and also the limits of the test itself when used in different types of masonry $[9,10]$.

The stress of the façade masonry has been determined by single flat jack test applied in two different parts of the surface, as shown in fig. 5-right. Test $\mathrm{F}_{\mathrm{i}, \mathrm{o}}$ has been performed both in- and outside the wall so to examine possible non uniform stress distribution and consequent flexural stresses. The flat jack testes highlighted the following outcomes:

- measured stress values were 1,9 MPa for $\mathrm{F}_{\mathrm{o}}$ test and 2,9 MPa for $\mathrm{F}_{\mathrm{i}, \mathrm{o}}$ test

- $\quad \mathrm{F}_{\mathrm{i}, \mathrm{o}}$ test measured the same stress value inside and outside the wall, thus pointing out no loads eccentricity and no flexural stresses

- stress values were consistent with a numerical evaluation run considering the loads above the tested masonry portions.

\section{Tie rods tension}

The analysis of the behaviour of an old masonry structure and, therefore, the diagnosis relative to its preservation and security, cannot be carried out except by determining the value of the axial tensile force which such metallic elements are 
subject to. Tie rods are free metallic bars, different in size and shape, normally fixed to stonework by means of bolts, plates or anchors. The tie rods tension is usually determined by considering the tie rod as a vibrating wire and measuring its first modal frequency. On the basis of this theoretical model, the axial tensile force $\mathrm{T}$ can be expressed as $[11,12]$ :

$$
\mathrm{T}=\left(4 \mathrm{~S} \gamma \mathrm{f}^{2} \mathrm{~L}^{2}\right) / \mathrm{g}
$$

where, referred to the tie rod, $\mathrm{S}$ is the cross section, $\gamma$ is the specific gravity, $\mathrm{f}$ is the first modal frequency, $\mathrm{L}$ is the length and $\mathrm{g}$ is the acceleration of gravity.

The force measuring is run in a dynamic way, which basically consists in the temporary fixing of one or more sensors (accelerometers) and in the acquisition of the signals following an impulse which the tie rod is given through a simple impact. The test, therefore, is non-destructive and very rapid. Moreover, it is well known that frequencies and modes of vibration are the best suited parameters to identify the structure's response, since they are determined by stiffness, masses and boundary conditions. Finally, it has to be considered that tie rods are easily excitable free structures, for which modal frequencies can be easily identified through spectral analysis.

The dynamic test has been carried out on the two tie rods linking the lateral chapels vault to the façade. Both the tie rods were underpinning a heavy chandelier, similar to those hanging from the accessing arches of the others lateral chapels, thus tests have been run both with and without chandeliers. Tests results are shown in Table 1.

The following outcomes were drawn:

- $\quad$ the two tie rods showed quite similar behaviour

- tie rods were subject to axial tensile stress only when the chandelier's load was taken into account

- the two tie rods didn't have static function, they were working as chandelier's supports only.

\section{Discussion}

The diagnostic campaign led to the conclusion that the Church's façade was not experiencing any meaningful shifting movement involving translation and

Table 1: $\quad$ Dynamic tests results.

\begin{tabular}{|l|c|c|c|c|c|}
\hline Tie rod & $\phi(\mathrm{mm})$ & $\mathrm{L}(\mathrm{m})$ & $\mathrm{f}(\mathrm{Hz})$ & $\mathrm{T}(\mathrm{kN})$ & $\sigma=\mathrm{T} / \mathrm{S}(\mathrm{MPa})$ \\
\hline $\begin{array}{l}\text { Right with } \\
\text { chandelier }\end{array}$ & 40 & 7.12 & 12.50 & 3188.5 & 253.9 \\
\hline $\begin{array}{l}\text { Right without } \\
\text { chandelier }\end{array}$ & 40 & 7.12 & 4.81 & 471.1 & 37.6 \\
\hline $\begin{array}{l}\text { Left with } \\
\text { chandelier }\end{array}$ & 40 & 7.12 & 9.63 & 1892.4 & 150.7 \\
\hline $\begin{array}{l}\text { Left without } \\
\text { chandelier }\end{array}$ & 40 & 7.12 & 4.81 & 471.1 & 37.6 \\
\hline
\end{tabular}


rotation, as the Public Administration was afraid of. This conclusion was supported by the following outcomes:

- cracks detected through visual inspection and then monitored for a 14 months period seemed to be affected most of all by temperature and seasonal variations, and didn't show remarkable opening trends

- dynamic tested tie rods were not working as structural members, they were only supporting the chandeliers

- the facade's masonry was not subject to non uniform stress distribution or to flexural stresses symptomatic of eccentric loads due to rotation, as pointed out by flat jack tests.

Moreover, NDTs permitted to get useful information on stone-fabric and characteristics of the façade's masonry:

- $\quad$ sonic tests and endoscopy pointed out that stone quality decreases from bottom to top and towards the inner layers of the masonry

- endoscopy highlighted that masonry non-homogeneities consist mostly of irregular stones and sporadically of potting compost, and sonic test didn't detect any meaningful void or macro cavity that has to be assumed as relevant discontinuity in masonry fabric

- flat jacks provided values of compressive stress quite uniform, and consistent with numerical evaluations.

The results of the diagnostic campaign also played an important role in the planning of the conservative intervention. The façade, although subject to several past restorations run throughout different constructive techniques and materials, was showing satisfactory static and structural condition, thus invasive consolidation or straightening were not needed. Continuous cracks monitoring was suggested, together with periodical non-destructive controls, in order to prevent any possible disease.

\section{Conclusions}

A diagnostic campaign has been planned and carried out on the façade of Santa Maria Church in Oristano, in order to get the higher number of reliable data about materials degrade and structural safety with limited costs and limited interference with the building functionality. Different types of NDTs have been selected and run: visual inspection, sonic test, flat jacks, rod ties dynamic test and crack pattern survey. The results pointed out the kind and the level of the degrade, and also suggested that injury depending on excessive load and on materials excessive deterioration was not present. In the light of the achieved results, the diagnostic campaign allowed the Public Administration to correctly plan the restoration program, and to get a realist estimation of restoration costs.

\section{References}

[1] Binda L., Zanzi L., Condoleo P., Cardani G. \& Anzani A., ND evaluation and monitoring of the Basilica of S. Lorenzo in Cremona. Proc. of RILEM SACoMaTiS 2008, vol. 2, pp. 737-746, 2008. 
[2] Binda L., Cantini L., Tiraboschi C. \& Amigoni C., Non-destructive investigation for the conservation design of a Monastery near Bergamo (Italy). Proc. of RILEM SACoMaTiS 2008, vol. 2, pp. 797-806, 2008.

[3] Ortolani B., Del Monte E., Galano L. \& Vignoli A., Structural identification of existing masonry buildings. Proc. of RILEM SACoMaTiS 2008, vol. 2, pp. 903-912, 2008.

[4] Colla C., de Miranda S. \& Ubertini F., On site diagnostic investigation for the assessment of the House of the Wooden Partition, in Herculaneum. Proc. of RILEM SACoMaTiS 2008, vol. 2, pp. 945-954, 2008.

[5] Abbaneo S., Binda L., Berra M. \& Fatticcioni A., Non-destructive evaluation of brick masonry structures: calibration of sonic wave propagation procedures. Proc. of the Int. Symp. NDT in Civil Eng., Berlin, vol. 2, pp. 1173-1179, 1995.

[6] Berra M., Binda L., Anti L. \& Fatticcioni A., Utilisation of sonic tests to evaluate damaged and repaired masonries. Proc. of NDT Evaluation of Civil Struct. and Mat., Boulder, Colorado, pp. 329-338, 1992.

[7] Vintzileou E., Miltiadou-Fezans A., Palieraki V. \& Delinikolas N., The use of radar techniques and endoscopy in investigating old masonry: the case of Dafni Monastery. Proc. of the 4th Int. Sem. on Struct. Analysis of Historical Constr., Balkema: Rotterdam, vol. 2, pp. 351-360, 2004.

[8] Alavalkama I., Aura S. \& Palmqvist H., (eds.) Endoscopy as a tool in Architecture. Proc. of the 1st Europ. Archit. Endoscopy Assoc. Conf., Tampere, Finland, p. 196, 1993.

[9] Binda L. \& Tiraboschi C., Flat-Jack Test: a slightly destructive technique for the diagnosis of brick masonry and stone masonry structures. Int. J. for Rest. of Build. and Monum., 5(5), pp. 449-472, 1999.

[10] Binda L., Tiraboschi C. \& Anzani A., Flat-jack methods applied to historic masonries. Int. Work. on Site Control and NDE of Masonry Struct. and Mat., RILEM Technical Committee, 177 MDT, Mantova, Italy, 2001.

[11] Blasi C. \& Sorace S., Determining the axial force in metallic rods. Struct. Eng. Int., 4(4), pp. 241-246, 1994.

[12] Lagomarsino S. \& Calderini C., The dynamical identification of the tensile force in ancient tie-rods. Eng. Struct., 27(6), pp. 846-856, 2005. 